RESEARCH ARTICLE

\title{
Periodontal Diseases in Children and Adolescents Affected by Systemic Disorders - A Literature Review
}

\author{
Triantafyllia Vagdouti $^{1}$ and Georgios Tsilingaridis ${ }^{2 *}$
}

${ }^{1}$ Private Practice, Greece

${ }^{2}$ Division of Pediatric Dentistry, Department of Dental Medicine, Karolinska Institute, Sweden

*Corresponding author: Dr. Georgios Tsilingaridis, DDS, PhD, Division of Pediatric Dentistry, Department of Dental Medicine, Karolinska Institute, Alfred Nobels alle 8, SE-141-04 Huddinge, Sweden, Tel: +46-8-52488029, E-mail: georgios.tsilingaridis@ ki.se

\begin{abstract}
Objective: The purpose of this study was to review the current literature concerning periodontal disease in children and adolescents associated with the most common systemic disorders. The etiology of the systemic diseases, prevalence and incidence, microbiology, manifestations of the disease, oral symptoms and the possible therapeutic approaches will be discussed.

Background data: The most frequent form of periodontal diseases in children and adolescents is plaque-associated gingivitis, while periodontitis occurs seldom. When a systemic disorder is present, periodontitis can appear as a manifestation, as the immune system is unable to successfully defend against bacteria.

Methods: Medline database (via PubMed) was searched from 1992 till present, using MeSH terms. Moreover, other sources were taken from the references of the selected papers and hand search was also done on the scientific journal Periodontology 2000.

Results: According to the International Workshop in Periodontics classification (1999), systemic disorders are divided into hematological and genetic disorders. Hematological disorders include: Acquired neutropenia and Leukemia, while genetic disorders include: Familial and cyclic neutropenia, Down syndrome, Leukocyte adhesion deficiency syndrome, PapilIon-Lefèvre syndrome, Chédiak-Higashi syndrome, Histiocytosis syndromes, Glycogen storage disease, Infantil genetic agranulocytosis, Cohen syndrome, Ehlers-Danlos syndrome and Hypophosphatasia.

Conclusion: This review updates the information of a range of systemic disorders that need cooperation between different medical and dental specialties for the best outcome of the children's general and oral health. Prevention and correct therapeutic approach are important for the management of individuals that belong to this category.
\end{abstract}

\author{
Keywords \\ Periodontal disease, Systemic disorders, Children, Adoles- \\ cents
}

\section{Introduction}

Periodontal diseases are inflammatory reactions that affect the supporting tissues of the teeth, which consist of: Gingiva, periodontal ligament, root cementum and alveolar bone. In children, the most common form, belonging to the classification of periodontal disease, is plaque-associated gingivitis [1], which is reversible when the plaque is removed but, in a few cases, a more serious destruction with bone loss is observed [2]. Microbial dental plaque and the presence of periodontal pathogens are necessary for the initiation of periodontal disease, but the host defense is the important factor that affects the progression and severity of periodontitis in individuals affected by systemic diseases [3]. Some of the periodontal pathogens present in the periodontal pockets were found to be Actinobacillus actinomycetemcomitans, Prevotella intermedia, Eikenella corrodens and Capnocytophaga sputigena [4]. Aggressive form of periodontal disease in children and adolescents, resulting in premature tooth loss, is uncommon and is often associated with chronic diseases and disabilities that have a major impact on the immune system $[5,6]$. The age of onset is early, during or after the eruption of primary dentition [7].

The treatment of periodontal disease in children 
Table 1: Periodontal diseases associated with hematological disorders.

\begin{tabular}{|l|l|l|l|}
\hline Disorder & Etiology & Clinical oral signs/symptoms & Therapy \\
\hline $\begin{array}{l}\text { Chronic benign } \\
\text { neutropenia }\end{array}$ & $\begin{array}{l}\text { Decrease in absolute number of } \\
\text { neutrophils }\end{array}$ & $\begin{array}{l}\text { Oral ulcerations } \\
\text { Chronic gingivitis } \\
\text { Chronic periodontitis }\end{array}$ & $\begin{array}{l}\text { Professional cleanings for dental } \\
\text { plaque control and removal of } \\
\text { calculus }\end{array}$ \\
\hline Leukemia & $\begin{array}{l}\text { Uncontrolled proliferation of white } \\
\text { blood cells }\end{array}$ & $\begin{array}{l}\text { Gingival swelling bleeding Oral } \\
\text { ulcerations }\end{array}$ & $\begin{array}{l}\text { Plaque control, mechanical } \\
\text { debridement }\end{array}$ \\
\hline
\end{tabular}

with systemic disorders is a challenge. It is important that the correct diagnosis is made for the appropriate treatment to be given. A thorough medical and dental history should be done and consultation with a physician is necessary [8].

According to the International Workshop in 1999, periodontitis as a manifestation of systemic diseases is a separate disease category [9]. The impaired host response in these subjects is a significant contributing factor that increases the susceptibility to periodontitis [10].

Systemic diseases are divided into hematological and genetic disorders [9].

The types of hematological disorders are:

1. Acquired neutropenia

2. Leukemias

3. Other

The types of genetic disorders are:

1. Familial and cyclic neutropenia

2. Down syndrome

3. Leukocyte adhesion deficiency syndrome

4. Papillon-Lefèvre syndrome

5. Chédiak-Higashi syndrome

6. Histiocytosis syndromes

7. Glycogen storage disease

8. Infantile genetic agranulocytosis

9. Cohen syndrome

10. Ehlers-Danlos syndrome (Types IV and VIII)

11. Hypophosphatasia

12. Other

The aim of this study was to review the current literature concerning periodontal disease in children and adolescents associated with the most common systemic disorders, and to give emphasis to the etiology of the systemic diseases, the clinical oral manifestations and the possible therapeutic approaches.

\section{Material and Methods}

The articles used were accessed from Medline database (via PubMed) using the following MeSH terms: "Periodontal Diseases", AND "Hematologic Diseases"
AND "Genetic Diseases, Inborn" AND "Child" AND "Adolescent". In addition to this search, selected references from a number of articles chosen from PubMed were included in the review. Select criteria limitations were: a) Article types: Clinical study or review; b) Publication date: 1992/01/01-2018/05/02; c) Age: Birth until 18 years; d) English language. The literature search continued by hand within the scientific journal Periodontology 2000 for articles that had the same criteria as with the electronic search.

\section{Results}

\section{Hematological disorders (Table 1).}

Neutropenia: Neutrophils are the major part of leukocytes and these cells are the first line of defense against infection [11]. They have a short lifespan and a significant decrease in the number of neutrophils or alterations in their function, may compromise the host's response to infection $[12,13]$. The number of polymorphonuclear leukocytes (PMNs) in the peripheral blood is below $1000 / \mathrm{mm}^{3}$ in infants, and below $1000 / \mathrm{mm}^{3}$ or $1500 / \mathrm{mm}^{3}$ in children [14].

Chronic benign neutropenia: Chronic benign neutropenia is characterized as a noncyclic neutropenia [15] and is the most common form of neutropenia of infants and children less than 4-years-old [16]. The incidence of this disease was estimated around 3.9 per 100.000 births [17]. Chronic benign neutropenia can follow a familial pattern as well, which would be in the form of an autosomal dominant condition that begins in infancy and is usually characterized by a self-limiting course of 10-18 months. Under physiological conditions, the neutrophils that are present in the junctional epithelium help with the phagocytosis of the bacteria. This type of defense is not possible during the neutropenic phase of the disease, or other cells such as monocytes take over [5]. Individuals with this condition often present with otitis media, upper respiratory infections, lymphadenopathy, pneumonia and sepsis due to the decreased response to infections [16].

The oral clinical picture can be recurrent oral ulcerations, chronic gingivitis with areas of desquamation and chronic periodontitis depending on the severity of the neutropenia [16]. In some cases, oral infection is quite severe [18]. Fortunately, as these individuals get older, the risk of infection is greatly reduced [16].

The maintenance therapy of chronic benign neutropenia occurs with granulocyte colony-stimulating factor 
[19]. Periodontal treatment includes the efficient control of dental plaque and calculus with regular professional cleaning [5].

Leukemia: Leukemia is caused by uncontrolled proliferation of white blood cells that infiltrate the tissues and cause enlargement of spleen, liver and lymph nodes. Leukemias can be acute or chronic, and they are classified according to the leucocyte type (granulocytes, monocytes, lympohcytes) involved [20]. Typically, acute lymphocytic leukemia is the most common form of childhood leukemia, although it is less likely to manifest oral lesions [21]. It has been reported that acute myeloblastic and lymphoblastic leukemia account for approx- imately $50 \%$ of all childhood malignant diseases [22]. Anaemia, infections and thrombocytopenia are usually present due to impaired marrow function [20].

One of the first signs of acute myeloblastic leukemia and acute lymphocytic leukemia can be generalized gingival swelling, bleeding and oral ulcerations [22]. In acute lymphocytic leukemia, tooth mobility can be a rare symptom [21].

The treatment for leukemia is chemotherapy and some acute leukemias respond well [23].

It is important that, prior to chemotherapy, the patient must undergo a dental examination and eliminate possible sources of periodontal infection by means of

Table 2: Periodontal diseases associated with genetic disorders.

\begin{tabular}{|c|c|c|c|}
\hline Disorder & Etiology & Clinical oral signs/symptoms & Therapy \\
\hline $\begin{array}{l}\text { Familial and cyclic } \\
\text { neutropenia }\end{array}$ & $\begin{array}{l}\text { ELANE mutation, cyclical } \\
\text { decrease in the number of } \\
\text { circulating neutrophils }\end{array}$ & $\begin{array}{l}\text { Oral ulcers } \\
\text { Gingival inflammation } \\
\text { Severe periodontitis }\end{array}$ & $\begin{array}{l}\text { Mechanical debridement } \\
\text { monthly and during neutropenic } \\
\text { episodes chlorhexidine rinsing }\end{array}$ \\
\hline Down syndrome & $\begin{array}{l}\text { Trisomy chromosome } 21, \\
\text { reduced chemotaxis and } \\
\text { impaired phagocytosis }\end{array}$ & $\begin{array}{l}\text { Gingivitis } \\
\text { Necrotizing ulcerative gingivitis } \\
\text { Severe periodontitis } \\
\text { Tooth mobility }\end{array}$ & $\begin{array}{l}\text { Preventive treatment and } \\
\text { periodontal therapy }\end{array}$ \\
\hline $\begin{array}{l}\text { Leukocyte adhesion } \\
\text { deficiency syndrome }\end{array}$ & $\begin{array}{l}\text { Defects in adhesion receptors } \\
\text { of the white blood cells and } \\
\text { impaired phagocytosis }\end{array}$ & $\begin{array}{l}\text { Type 1: Severe gingival inflammation } \\
\text { Rapidly progressive periodontitis } \\
\text { Type 2: Chronic severe periodontitis }\end{array}$ & $\begin{array}{l}\text { Periodontal treatment with } \\
\text { or without antibiotics, often } \\
\text { followed by extraction of } \\
\text { primary or permanent teeth }\end{array}$ \\
\hline $\begin{array}{l}\text { Papillon-Lefèvre } \\
\text { syndrome }\end{array}$ & $\begin{array}{l}\text { Mutation of gene encoding } \\
\text { for cathepsin-c, impaired } \\
\text { neutrophil function }\end{array}$ & $\begin{array}{l}\text { Aggressive periodontitis } \\
\text { Premature loss of teeth }\end{array}$ & $\begin{array}{l}\text { Conventional periodontal } \\
\text { treatment with antibiotics } \\
\text { according to the dentition } \\
\text { involved and extraction of } \\
\text { primary teeth } 6 \text { months prior to } \\
\text { eruption of permanent teeth if } \\
\text { indicated }\end{array}$ \\
\hline $\begin{array}{l}\text { Chédiak-Higashi } \\
\text { syndrome }\end{array}$ & Mutation in LYST gene & $\begin{array}{l}\text { Oral ulcerations } \\
\text { Severe gingivitis } \\
\text { Early-onset periodontitis }\end{array}$ & Challenging periodontal therapy \\
\hline $\begin{array}{l}\text { Histiocytosis } \\
\text { syndromes }\end{array}$ & $\begin{array}{l}\text { Abnormal proliferation of bone } \\
\text { marrow-derived histiocytes }\end{array}$ & $\begin{array}{l}\text { Periodontitis } \\
\text { Alveolar bone loss replaced by soft } \\
\text { tissue } \\
\text { Oral ulceration } \\
\text { Premature loss of teeth }\end{array}$ & $\begin{array}{l}\text { Conventional periodontal } \\
\text { therapy and surgical therapy } \\
\text { in mandibular lesions in some } \\
\text { cases }\end{array}$ \\
\hline $\begin{array}{l}\text { Glycogen storage } \\
\text { disease }\end{array}$ & $\begin{array}{l}\text { Type } 1 b \text { : Deficiency of } \\
\text { glucose-6-phosphate } \\
\text { translocase }\end{array}$ & $\begin{array}{l}\text { Oral ulcers } \\
\text { Hyperplastic gingiva } \\
\text { Periodontal infections } \\
\text { Prolonged bleeding }\end{array}$ & $\begin{array}{l}\text { Preventive treatment and } \\
\text { control of gingival disease }\end{array}$ \\
\hline $\begin{array}{l}\text { Severe congenital } \\
\text { neutropenia }\end{array}$ & ELANE and HAX1 mutations & $\begin{array}{l}\text { Gingival inflammation } \\
\text { Increased probing depth } \\
\text { Severe alveolar bone loss in both } \\
\text { dentitions }\end{array}$ & $\begin{array}{l}\text { Scaling and root planing, use of } \\
\text { antimicrobial agents }\end{array}$ \\
\hline Cohen syndrome & Mutation in the VPS13B gene & Periodontal disease & $\begin{array}{l}\text { Prevention and conventional } \\
\text { periodontal therapy }\end{array}$ \\
\hline $\begin{array}{l}\text { Ehlers-Danlos } \\
\text { syndrome (Type IV } \\
\text { and VIII) }\end{array}$ & $\begin{array}{l}\text { Type IV: Mutation in type III } \\
\text { collagen } \\
\text { Type VIII: mutation in } \\
\text { chromosome } 12 \mathrm{p} 13\end{array}$ & $\begin{array}{l}\text { Severe periodontitis } \\
\text { Prolonged bleeding } \\
\text { Delayed healing }\end{array}$ & $\begin{array}{l}\text { Chemical and mechanical } \\
\text { plaque control }\end{array}$ \\
\hline Hypophosphatasia & $\begin{array}{l}\text { Mutation in tissue nonspecific } \\
\text { alkaline phosphatase activity }\end{array}$ & $\begin{array}{l}\text { Absence of root cementum } \\
\text { Premature exfoliation of deciduous } \\
\text { teeth }\end{array}$ & $\begin{array}{l}\text { Possible extraction of primary } \\
\text { teeth and more conservative } \\
\text { treatment on permanent teeth }\end{array}$ \\
\hline
\end{tabular}


periodontal therapy. A multidisciplinary approach is essential for any dental intervention [24]. Periodontal treatments of patients with leukemia, involves plaque control and mechanical debridement in order to prevent bacteremia and gingival bleeding [25].

\section{Genetic disorders (Table 2).}

Familial and cyclic neutropenia: It is a rare autosomal dominant disorder characterized by a cyclical decrease in the number of circulating neutrophils, because of ELANE mutation encoding neutrophil elastase [26]. The decrease in the number of neutrophils occurs every 21 days and lasts for 3-6 days at a time [27]. Its incidence is $0.5-1$ case per million [16].

The clinical symptoms during this phase are: Fever, malaise, headache, anorexia, pharyngitis, lymphadenopathy, sepsis, ulcers of the oral mucous membrane and gingival inflammation [16]. Patients are prone to severe periodontal disease [28].

The maintenance therapy of cyclic neutropenia occurs with granulocyte colony-stimulating factor, but the only curative treatment is hematopoietic stem cell transplantation $[29,30]$.

It is recommended that professional removal of dental plaque and calculus should be done monthly and during the neutropenic episodes, antibiotics may be given in order to prevent oral infection [23].

Down syndrome: Down syndrome is a chromosomal abberation resulting from trisomy of chromosome 21. The most common manifestations of the syndrome are mental retardation, and a variety of morphological characteristics [31]. Down syndrome is a congenital autosomal anomaly affecting 1 in 600 to 1 in 1000 live births [32]. Approximately $40 \%$ of infants with Down syndrome suffer from heart disease and 1 in 200 children are present with leukemia (mostly the acute lymphocytic type) [33]. Furthermore, children with Down syndrome feature growth retardation, hormonal disturbances, obesity and neuropsychiatric disorders [34]. They have also increased susceptibility to infection due to impaired host response characterized by reduced chemotaxis, impaired phagocytosis, and disturbances in $\mathrm{T}$ - and B-cell subpopulations [35].

Some of the oral conditions associated with Down syndrome are: "V" shaped palate, lower lip everted, mouth breathing with drooling, angular cheilitis, fissured tongue, microdontia, hypodontia, taurodontism, delayed eruption, spacing, bruxism and periodontal disease [32]. Periodontal anomalies in Down syndrome include marginal gingivitis, acute necrotizing gingivitis, severe periodontitis with furcation involvement in the molar area, tooth mobility and frequent loss of teeth in the mandibular anterior area [32].

Surveys have shown that children and adolescents with Down syndrome have a higher prevalence and se- verity of periodontal disease compared to healthy controls [32,36-38]. This prevalence and severity is not only due to poor oral hygiene and the presence of periodontal pathogens such as Porphyromonas gingivalis and Aggregatibacter actinomycetemcomitans [39], but also because of the impaired host response. Specifically, it has been found that subjects with this syndrome had increased levels of serum interleukin-2 (IL-2) receptors [40], prostaglandin E2 $[35,41]$, leukotriene B4 [35,42], matrix metalloproteinase-9 (MMP-9) [35], MMP-8 [43], Tumor necrosis factor- $\alpha$ (TNF- $\alpha$ ) and interferon- $\gamma$ (IFN- $\gamma$ ) in gingival crevicular fluid (GCF) compared to controls $[44,45]$. In addition to previous studies, Tsilingaridis, et al. [45] concluded from their research, that subjects with Down syndrome, show higher levels of T-helper 1 (Th) and Th2 and an altered relationship between Th1, IFN- $\gamma$, Th2 and IL-4 in GCF from the healthy controls. In another study, adolescents with Down syndrome were divided into a group with only gingivitis and another group with periodontitis and were compared with the equivalent control groups. Results showed that the amounts of MMPs in GCF were increased and that an altered relationship between MMP-8 and tissue inhibitors of metalloproteinases-2 (TIMP-2) exists [34]. There seems to be also an association between matrix MMPs and lymphocytes subpopulations, which may facilitate the migration of immune cells into periodontal tissue and contribute to its increased degradation [46]. It has been found that the prevalence of periodontal disease is higher when the subjects live in institutions rather than at home, and that they suffer from alveolar bone loss from childhood or adolescence, which becomes worse when they get older and reaches about 70\% [34].

Therefore, it is advisable to begin routine preventive treatment in patients with Down syndrome at an early age [47], in order to reduce periodontal tissue breakdown because except from the immune deficiency, these children are often unable to brush their teeth correctly and thus have control of bacterial plaque.

Leukocyte adhesion deficiency syndrome (LAD): $L A D$ is an inherited autosomal-recessive disorder characterized by defects in adhesion receptors of the white blood cells. Defects in the expression of glycoproteins adhesion molecules result in abnormalities in phagocytosis, and defect in the neutrophil's ability to leave the vascular space $[14,48]$. There are three main types of LAD. Type $I$ is caused by mutation in membrane $\beta_{2}$ integrin, type II has a defect in the expression of ligands for selectins, and type III has other defects including platelet aggregation abnormalities. The most common form is type I, and patients present recurrent bacterial infections, impaired pus formation and impaired wound healing $[7,49]$.

The oral manifestations in type I include severe gingival inflammation and rapidly progressive periodontal destruction around the primary and the permanent 
teeth with tooth loss, whereas in type II the manifestations are in milder forms, except for the chronic severe periodontitis [50,51].

The treatment of choice is considered bone marrow transplantation. In recent years, gene therapy seems promising in order to treat severe immunodeficiencies [5].

Different kinds of therapeutical approaches have been suggested, for example periodontal treatment with or without antibiotics or even multiple extractions of teeth [14]. The management of the aggressive periodontitis in these patients is very challenging and many times unsuccessful.

Papillon-Lefèvre syndrome: This syndrome is a skin disorder, characterized by hyperkeratosis of the palms, the soles of the feet and rapidly progressive periodontitis that leads to early loss of the primary and permanent teeth. The disease is rare and is inherited as an autosomal-recessive trait with a prevalence in the general population of 1 to 3 or 4 per million [5,52]. A mutation of the gene encoding for Cathepsin- $\mathrm{C}$ is associated with the disease $[53,54]$. Cathepsin- $C$ functions as a key enzyme in the activation of serine proteases in immune and inflammatory cells [55]. Other features included are mental retardation, intracranial calcification and recurrent pyogenic infections [51]. Furthermore, this mutation affects the neutrophil responses to microbial pathogens, and causes an increase in the amount of PMNs, at sites of periodontal inflammation.

The aggressive periodontitis with premature loss of primary and permanent teeth is due to the immune alterations, a disturbed epithelial function in the gingival tissues and the presence of Aggregatibacter actinomycetemcomitans [56]. After eruption of the primary teeth, gingiva becomes inflamed and then it follows a rapid destruction of the periodontal tissues. When primary teeth are lost, the inflammation subsides, and gingivae return to a normal state. The same pattern is applied to the permanent teeth. In the radiographic examination "floating teeth" are observed, due to alveolar bone loss.

A combination of conventional periodontal therapy (mechanical debridement) and antibiotics of amoxicillin or amoxicillin and clavulanic acid, with a dose of 20-50 $\mathrm{mg} / \mathrm{kg} /$ day or $20-40 \mathrm{mg} / \mathrm{kg} /$ day every 8 hours in primary dentition, and in permanent dentition amoxicillin with a dose of $20-50 \mathrm{mg} / \mathrm{kg} /$ day plus metronidazole, with a dose of $15-35 \mathrm{mg} / \mathrm{kg} /$ day, every 8 hours respectively, seems to control the periodontal disease in these patients [56]. In cases of severe inflammation of primary teeth, extraction is indicated at least 6 months prior to the eruption of first permanent teeth [56]. Ullbro evaluated an oral treatment protocol, which showed that compliance of the patient had a strong impact on the bleeding surfaces and pathological periodontal pockets. In the same study, it was revealed that there was no correlation between the severity of skin lesions and the severity of periodontitis.

Chédiak-Higashi syndrome: Chédiak-Higashi syndrome is a rare, often fatal, autosomal recessive genetic disorder, caused by mutation in the lysosomal trafficking regulator gene (LYST) [57]. This disorder features abnormal giant lysosomal granules within the leukocytes. Furthermore, as the neutrophils exhibit reduced content of hydrolytic enzymes, this results in intracellular killing of phagocytosed bacteria [58]. This mutation result often in multiple recurrent infections and lymphoproliferative disorders in multiple organs, bleeding abnormalities [58] and muscle weakness [59].

According to the literature, severe gingivitis, oral ulcerations and early onset periodontitis, are the most common oral manifestations $[5,16]$.

Bone marrow transplantation is the treatment choice, and thus the predisposition to periodontal disease can be diminished $[48,59,60]$.

Unfortunately, most of the cases because of severe destruction of the periodontal tissues, will result in tooth extraction [16]. Consequently, the response to periodontal treatment is related to the severity of the syndrome and the outcome in the severe forms of the syndrome might be unsuccessful [49].

Langerhans cell histiocytosis (Histiocytosis X): Langerhans cell histiocytosis is caused by an abnormal proliferation of bone marrow-derived histiocytes, with leucocytes, eosinophils, neutrophils, lymphocytes, plasma cells and giant multi-nucleated cells. It is classified in three forms: Eosinophilic granuloma, Hand-SchüllerChristian disease, and Letterer-Siwe disease. Eosinophilic granuloma is the most frequent and benign and is characterized as a uni- or multifocal lesion in single or various bones. Hand-Schüller-Christian disease is present in children or young adults, featured with the characteristic triad of exophthalmos, osteolytic lesions of the cranium and diabetes insipidus. The third clinical form, Letterer-Siwe disease, is present in children under three-years-old and is very aggressive and fatal [61].

Clinical signs and symptoms in these children are: Periodontitis, loss of alveolar bone replaced by soft tissue, ulceration and necrosis of the oral mucosa, resembling necrotizing ulcerative periodontitis, and premature loss of teeth. Destruction of lamina dura results in the radiographic appearance of "floating teeth" $[20,48,51,62]$. In the fibrous tissue, there is an infiltrate of inflammatory cells of which the majority are histiocytes [61].

Treatment can be a combination of surgery, chemotherapy, radiotherapy, corticosteroids and antimitotic drugs [5,61]. Vincristine, cyclophosphamide and methotrexate, are drugs that are often used in these disorders [47]. 
A very thorough root scaling and planning is suggested in the affected areas. Localized and isolated mandibular lesions, that are common, maybe treated by surgical curettage, and if it results in a large bony defect, autologous bone grafts are suggested to decrease the risk of pathological fracture [61].

Glycogen storage diseases: These are rare metabolic disorders and cause the body to be less able to make enough glucose, or not be able to use glucose as a form of energy [63]. There are 18 known types of glycogen storage diseases. The subtype $1 \mathrm{~b}$ is an autosomal-recessive disease caused by a deficiency of microsomal glucose-6-phosphate translocase. Typical "doll-like" facial appearance [64], hypoglycemia, hyperlipidemia, lactic acidosis, gout and bleeding episodes are included in the manifestations of the disease [65].

Patients also feature neutropenia, and therefore are more susceptible to infections, including oral ulcers, hyperplastic gingiva and periodontal infections. Prolonged bleeding is a possible complication in this type of patients.

The treatment for neutropenia, that is granulocyte colony-stimulating factor, will reduce the frequency of infections [66-68].

Early preventive treatment including professional plaque removal and control of gingivitis is advisable [47].

Severe congenital neutropenia (SCN) or Kostmann syndrome or Infantile genetic agranulocytosis: SCN is a disease with an autosomal-recessive or dominant and in some cases sporadic inheritance pattern, manifesting the first years of life, characterized by low absolute neutrophil count $<1.500 / \mathrm{l}$, with severe recurrent bacterial infections and arrest of the myelopoiesis in the bone marrow at the level of promyelocyte/myelocyte stage [69]. The frequency is around 1-2 cases per million [16]. The gene mutations seen are: ELANE gene encoding neutrophil elastase, which is more common in the dominant or sporadic forms of the disease [26], and in the recessive form the HAX1 gene, which encodes the mitochondrial antiapoptotic protein HS1-associating protein X-1 [70]. Patients with ELANE mutations seem to present more severe forms of periodontal disease compared to patients with HAX1 or unknown mutations $[71,72]$. It has been found that the neutrophils in these diseases can also have qualitative deficiencies, such as in the antimicrobial protein pro-LL-37 and reduced level of the human neutrophil peptide 1-3 in the granules, which means that their antimicrobial activity is reduced [73].

The diagnosis occurs in infancy and the reported oral clinical findings are: Gingival inflammation, increased probing depth and severe alveolar bone loss both in primary and in permanent dentition [6,72]. The microbiology is not quite clear yet, although there is some evidence of the presence of $A$. actinomycetemcomitans and $P$. gingivalis in periodontal pockets [72].

The maintenance therapy of SCN occurs with granulocyte colony-stimulating factor, but the only curative treatment is hematopoietic stem cell transplantation $[29,30]$.

Recommended therapy is scaling and root planing, soft-tissue curettage and use of selected antimicrobial agents. Okada, et al. [28] reported that patients who received local antibiotic prophylaxis and controlled oral hygiene, showed improvement of gingival conditions.

Cohen syndrome: Cohen syndrome is a rare genetic disorder with an autosomal-recessive mode of transmission. It is caused by a mutation in the VPS13B gene. These patients have intellectual disability, developmental delay and their physical appearance is characteristic: Narrow hands and feet with long, slender fingers, often truncal obesity, and prominent upper central incisors [6].

The affected individuals have often granulocytopenia and neutropenia, resulting in vulnerability to infections, including periodontitis, but seem to be able to respond to severe bacterial infections [74]. Alaluusua, et al. [74] showed through their research in subjects with Cohen syndrome and chronic neutropenia, that early periodontal breakdown is a clinical feature of Cohen syndrome and that it does not depend on the severity of neutropenia, but on the age. They reported that young patients present better resistance to periodontitis than older ones.

Ehlers-Danlos syndrome (Types IV and VIII): It is a connective tissue disorder, which results mostly from an abnormality of type I or III collagen and affects the joints and skin. The prevalence is between 1 in 5000 and 1 in 10000 [75]. It has been classified into ten types according to the clinical symptoms and inheritance pattern [5]. Type IV or Vascular type and type VIII have been associated with severe periodontitis [49] and Type I predisposes to localized periodontitis [76]. Type IV has an autosomal dominant/recessive pattern and type VIII has an autosomal dominant pattern with a prevalence 1 in 50000 [75]. Type IV and VIII are characterized by skin hyperextensibility, fragility, scarring, joint hypermobility, normal to slightly increased bruising on mild trauma, early-onset periodontitis, gingival recessions and thin gingiva and/or absence of attached gingiva [77]. Type IV except from the previous manifestations, presents a life-threatening visceral and large vessel rupture [5,21]. Clinical symptoms of these types are similar, and the only way to distinguish them is the mutation in type III collagen metabolism, that is found in type IV [78]. Type VIII may be linked with a region on chromosome $12 \mathrm{p} 13$ [79]. Another study found that mutations in C1R or C1S may be responsible for Periodontal Ehlers-Danlos syndrome [77].

Type VIII has been associated with severe periodon- 
titis and premature loss of teeth $[5,76]$. Although Type IV also features as well severe periodontitis, it is the type VIII that is the most common type, presenting with severe periodontitis [49]. A defect in type III collagen found in type IV Ehlers-Danlos syndrome, can undermine the integrity of the periodontal apparatus as $9 \%$ of the gingival collagen and $16 \%-18 \%$ of the total collagen of the periodontium is composed of type III collagen [21]. Fusobacterium nucleatum has been found in active lesion sites [76].

There is no specific treatment for the syndrome, although for the patients in whom bleeding abnormality is recognized, desmopressin can prevent or decrease the risk of hemorrhage during surgical procedures [79]. Because of the deficient collagen biosynthesis, aggressive periodontitis can occur at an early age. During dental therapy, these patients need special caution because of the fragility of the tissues and the healing after periodontal treatment can be slow and inadequate [47]. So, chemical and mechanical plaque control is advised for prevention of periodontitis [76].

Hypophosphatasia: Hypophosphatasia is a rare metabolic autosomal disorder with a deficiency in tissue nonspecific alkaline phosphatase activity. This deficiency results in accumulation of extracellular pyrophosphate and causes the inhibition of skeletal and dental mineralization [80-83]. There are six different clinical forms of the disease, and they are divided according to the age of the patient and degree of severity. It may appear in a perinatal from, a severe infantile form within 6 months of life, a milder form occurring in childhood or late adolescence within 6-24 months, an adult form, a form of odontohypophosphatasia or as a rare benign prenatal form [84]. Childhood hypophosphatasia is the most common form in dentistry characterized by delayed walking, short stature, bulging eyes and a "beaten-copper" appearance of the calvarium $[84,85]$.

Patients that belong to the odontohypophosphatasia form, present taurodontism and there is absence of root cementum, which leads to inadequate attachment of the tooth to the periodontal ligament and premature exfoliation of deciduous teeth $[84,86,87]$.

Patients that feature the infantile or childhood form, share a common clinical symptom, premature exfoliation of teeth [84]. There is no increased gingival inflammation or periodontitis and the immune response to infections is not defective [88].

Treatment varies depending on its stage and classification and focus on treating bony deformities. Control of hypercalcemia is important and vitamin D supplements can improve the clinical presentation [48].

Regarding the dental therapeutical approach, it is often needed to extract primary teeth with high mobility, but on the permanent dentition it is suggested to follow a more conservative therapy and try to keep the teeth [5].

\section{Conclusion}

The treatment of periodontitis in young patients with systemic diseases is many times challenging and a close collaboration with other specialties of medicine is required [6]. These children have often a decreased response to inflammation, and if antibiotic therapy is given, the results are many times not the expected [89]. Furthermore, the medications for the treatment of the systemic disorder can have side effects with oral manifestations, such as oral mucositis during cytostatic chemotherapy [90]. Therefore, the main goal for the dentist when treating periodontal disease in these patients is to control the microbial dental plaque and offer an adequate maintenance treatment $[6,56,76]$.

Compliance to a treatment protocol with secondary prevention as in patients with Papillon-Lefèvre syndrome seems significant for a successful outcome [56]. The findings of Tsilingaridis [34] suggest that in children with Down syndrome, it is important to provide a primary preventive treatment before the development of periodontitis.

Periodontal diseases and especially periodontitis is often the major clinical characteristic of these systemic disorders. Therefore, if a child or adolescent has periodontitis, the dentist should make a differential diagnosis between periodontitis because of familial aggregation and periodontitis because of diminished host response due to a systemic disorder. In such a case, a referral and cooperation with the pediatrician is needed for the best outcome of the child's general health. Also the experience of a specialist in Periodontics is of value in such cases in order to customize the therapeutic and preventive approach for each patient.

\section{References}

1. Jenkins WM, Papapanou PN (2001) Epidemiology of periodontal disease in children and adolescents. Periodontol 2000 26: 16-32.

2. Darby I, Curtis M (2001) Microbiology of periodontal disease in children and young adults. Periodontol 2000 26: 33-53.

3. Kinane DF (1999) Periodontitis modified by systemic factors. Ann Periodontol 4: 54-64.

4. Committee on research, science and therapy of the American Academy of Periodontology (1996) Position Paper: Periodontal disease of children and adolescents. J Periodontol 67: 57-62.

5. Meyle J, Gonzáles JR (2001) Influences of systemic diseases on periodontitis in children and adolescents. Periodontol 2000 26: 92-112.

6. Knocht A, Albandar JM (2014) Aggressive forms of periodontitis secondary to systemic disorders. Periodontol 2000 65: 134-148.

7. Meyle J (1994) Leukocyte adhesion deficiency and prepubertal periodontitis. Periodontol 2000 6: 26-36.

8. Albandar JM (2014) Aggressive and acute periodontal diseases. Periodontol 2000 65: 7-12. 
9. Armitage GC (1999) Development of a classification system for periodontal diseases and conditions. Ann Periodontol 4 $1-6$.

10. Taubman MA, Valverde $P$, Han X, Kawai T (2005) Immune response: The key to bone resorption in periodontal disease. J Periodontol 76: 2033-2041.

11. Pillay J, den Braber I, Vrisekoop N, Kwast LM, de Boer RJ, et al. (2010) In vivo labeling with $2 \mathrm{H} 2 \mathrm{O}$ reveals a human neutrophil lifespan of 5.4 days. Blood 116: 625-627.

12. Ryder MI (2010) Comparison of neutrophil functions in aggressive and chronic periodontitis. Periodontol 2000 53: 124-137.

13. Scott DA, Krauss J (2012) Neutrophils in periodontal inflammation. Front Oral Biol 15: 56-83.

14. Oh TJ, Eber R, Wang HL (2002) Periodontal diseases in the child and adolescent. J Clin Periodontol 29: 400-410.

15. Bernini J (1996) Diagnosis and management of chronic neutropenia during childhood. Pediatr Clin North Am 43: 773-792.

16. Deas DE, Mackey SA, McDonnell HT (2003) Systemic disease and periodontitis: Manifestations of neutrophil dysfunction. Periodontol 2000 32: 82-104.

17. Rajantie J, Kurki S, Juvonen E, Hovi L (1993) Prolonged pure granulocytopenia in children. Acta Paediatr 82: 839842.

18. Buduneli N, Cogulu D, Kardesler L, Kütükçüler N (2006) Dental findings and treatment in consanguinity associated congenital chronic familial neutropenia. J Clin Pediatr Dent 31: 123-126.

19. Goodnough LT, Anderson KC, Kurtz S, Lane TA, Pisciotto PT, et al. (1993) Indications and guidelines for the use of hematopoietic growth factors. Transfusion 33: 944-959.

20. Kinane DF, Marshall GJ (2001) Periodontal manifestations of systemic disease. Aust Dent J 46: 2-12.

21. Hartsfield JK Jr (1994) Premature exfoliation of teeth in childhood and adolescence. Adv Pediatr 41: 453-470.

22. Clerehugh $V$, Tugnait $A$ (2001) Diagnosis and management of periodontal diseases in children and adolescents. Periodontol 2000 26: 146-168.

23. Jordan RC (2004) Diagnosis of periodontal manifestations of systemic diseases. Periodontol 2000 34: 217-229.

24. (2000) Parameter on periodontitis associated with systemic conditions. American Academy of periodontology. J Periodontol 71: 876-879.

25. Holmstrup P, Glick M (2002) Treatment of periodontal disease in the immunodeficient patient. Periodontol 2000 28: 190-205.

26. Li FQ, Horwitz M (2001) Characterization of mutant neutrophil elastase in severe congenital neutropenia. J Biol Chem 276: 14230-14241.

27. Horwitz M, Benson KF, Person RE, Aprikyan AG, Dale DC (1999) Mutations in ELA2, encoding neutrophil elastase, define a 21-day biological clock in cyclic haematopoiesis. Nat Genet 23: 433-436.

28. Okada M, Kobayashi M, Hino T, Kurihara H, Miura K (2001) Clinical periodontal findings and microflora profiles in children with chronic neutropenia under supervised oral hygiene. J Periodontol 72: 945-952.

29. Zeidler C, Schwinzer B, Welte K (2003) Congenital neutropenias. Rev Clin Exp Hematol 7: 72-83.
30. Carlsson G, Winiarski J, Ljungman $P$, Ringdén $O$, Mattsson $\mathrm{J}$, et al. (2011) Hematopoietic stem cell transplantation in severe congenital neutropenia. Pediatr Blood Cancer 56: 444-451.

31. Pueschel SM, Annerén G, Durlach R, Flores J, Sustrová M, et al. (1995) Guidelines for optical medical care of persons with down syndrome. International league of societies for persons with mental handicap (ILSMH). Acta Paediatr 84: 823-827.

32. Desai SS (1997) Down syndrome: A review of the literature. Oral Surg Oral Med Oral Pathol Oral Radiol Endod 84: 279285.

33. Wilson MD (1994) Special considerations for patients with down syndrome. ODAJ 184: 24-25.

34. Tsilingaridis G, Yucel-Lindberg T, Modéer T (2013) Altered relationship between MMP-8 and TIMP-2 in gingival crevicular fluid in adolescents with down's syndrome. J Periodontal Res 48: 553-562.

35. Tsilingaridis G, Yucel-Lindberg T, Modéer T (2003) Enhanced levels of prostaglandin E2, leukotriene B4, and matrix metalloproteinase-9 in gingival crevicular fluid from patients with down syndrome. Acta Odontol Scand 61: 1 54-158.

36. Genco RJ, Löe H (1993) The role of systemic conditions and disorders in periodontal disease. Periodontol 2000 2: 98-116.

37. Hennequin M, Faulks D, Veyrune JL, Bourdiol P (1999) Significance of oral health in persons with down syndrome: A literature review. Dev Med Child Neurol 41: 275-283.

38. Gabre P (2000) Studies on oral health in mentally retarded adults. Swed Dent J Suppl 142: 1-48.

39. Barr-Agholme M, Dahllöf G, Linder L, Modéer T (1992) Actinobacillus actinomycetemcomitans, capnocytophaga and porphyromonas gingivalis in subgingival plaque of adolescents with down's syndrome. Oral Microbiol Immunol 7: 244-248.

40. Cutando-Soriano A, Góomez-Moreno G, Bravo M (1993) Free interleukin-2 receptors in children with trisomy 21 (Down's syndrome) and different levels of periodontal disease. Int J Paediatr Dent 8: 177-180.

41. Offenbacher S, Heasman PA, Collins JG (1993) Modulation of host $\mathrm{PGE}_{2}$ secretion as a determinant of periodontal disease expression. J Periodontol 64: 432-444.

42. Heasman PA, Collins JG, Offenbacher S (1993) Changes in crevicular fluid levels of interleukin-1 beta, leukotriene $\mathrm{B}_{4}$, prostaglandin $\mathrm{E}_{2}$, thromboxane $\mathrm{B} 2$ and tumour necrosis factor alpha in experimental gingivitis in humans. J Periodont Res 28: 241-247.

43. Halinen S, Sorsa T, Ding Y, Ingman T, Salo T, et al. (1996) Characterization of matrix metalloproteinase (MMP-8 and9) activities in the saliva and in gingival crevicular fluid of children with down's syndrome. J Periodontol 67: 748-754.

44. Murphy M, Friend DS, Pike-Nobile L, Epstein LB (1992) Tumor necrosis factor-alpha and IFN-gamma expression in human thymus. Localization and overexpression in down syndrome (trisomy 21). J Immunol 149: 2506-2512.

45. Tsilingaridis G, Yucel-Lindberg T, Modéer T (2012) T-helperrelated cytokines in gingival crevicular fluid from adolescents with Down syndrome. Clin Oral Invest 16: 267-273.

46. Tsilingaridis G, Yucel-Lindberg T, Concha Quezada $H$, Modéer $T$ (2014) The relationship between matrix metalloproteinases (MMP-3,-8,-9) in serum and peripheral 
lymphocytes (CD8+,CD56+) in Down syndrome children with gingivitis. J Periodont Res 49: 742-750.

47. Pizzo G, Lo Re D, Piscopo MR, Pizzo I, Giuliana G (2009) Genetic disorders and periodontal health: A literature review. Med Sci Monit 15: 167-178.

48. Sollecito TP, Sullivan KE, Pinto A, Stewart J, Korostoff J (2005) Systemic conditions associated with periodontitis in childhood and adolescence. A review of diagnostic possibilities. Med Oral Patol Oral Cir Bucal 10: 142-150.

49. Hart TC, Atkinson JC (2007) Mendelian forms of periodontitis. Periodontol 2000 45: 95-112.

50. Etzioni A, Tonetti M (2000) Leukocyte adhesion deficiency II-from A to almost Z. Immunol Rev 178: 138-147.

51. Dababneh R, Al-Wahadneh AM, Hamadneh S, Khouri A, Bissada NF (2008) Periodontal manifestation of leukocyte adhesion deficiency type I. J Periodontol 79: 764-768.

52. Hart TC, Shapira L (1994) Papillon-Lefèvre syndrome. Periodontol 2000 6: 88-100.

53. Hart TC, Hart PS, Bowden DW, Michalec MD, Callison SA, et al. (1999) Mutations of the cathepsin C gene are responsible for Papillon-Lefèvre syndrome. J Med Genet 36: 881-887.

54. Toomes C, James J, Wood AJ, Wu CL, McCormick D, et al. (1999) Loss-of-function mutations in the cathepsin C gene result in periodontal disease and palmoplantar keratosis. Nat Genet 23: 421-424.

55. Hewitt C, McCormick D, Linden G, Turk D, Stern I, et al. (2004) The role of cathepsin C in Papillon-Lefèvre syndrome, prepubertal periodontitis, and aggressive periodontitis. Hum Mutat 23: 222-228.

56. Ullbro C, Brown A, Twetman S (2005) Preventive periodontal regiment in Papillon-Lefèvre syndrome. Pediatr Dent 27: 226232.

57. Nagle DL, Karim MA, Woolf EA, Holmgren L, Bork P, et al. (1996) Identification and mutation analysis of the complete gene for chediak-higashi syndrome. Nat Genet 14: 307-311.

58. Huizing M, Anikster Y, Gahl WA (2001) Hermansky-pudlak syndrome and chediak-higashi syndrome: Disorders of vesicle formation and trafficking. Thromb Haemost 86: 233-245.

59. Introne W, Boissy RE, Gahl WA (1999) Clinical, molecular, and cell biological aspects of chediak-higashi syndrome. Mol Genet Metab 68: 283-303.

60. Abdulsalam AH, Sabeeh N, Bain BJ (2012) Bone marrow aspirate in Chédiak-Higashi syndrome. Am J Hematol 87: 100.

61. Madrigal-Martínez-Pereda C, Guerrero-Rodríguez V, Guisado-Moya B, Meniz-García C (2009) Langerhans cell histiocytosis: Literature review and descriptive analysis of oral manifestations. Med Oral Patol Oral Cir Buccal 14: E222-E228.

62. Regezi JA, Sciubba JJ (1993) Oral pathology: Clinicalpathological correlations. Philadelphia: WB Saundeers 413-416.

63. Hicks J, Wartchow E, Mierau G (2011) Glycogen storage diseases: A brief review and update on clinical features, genetic abnormalities, pathologic features, and treatment. Ultrastruct Pathol 35: 183-196.

64. Damian Drążewski, Małgorzata Grzymisławska, Katarzyna Korybalska, Natasza Czepulis, Marian Grzymisławski, et al. (2017) Oral health status of patients with lysosomal storage diseases in Poland. Int J Environ Res Public Health 14: 281.
65. Wolfsdorf JI, Holm IA, Weinstein DA (1999) Glycogen storage diseases. Phenotypic, genetic and biochemical characteristics and therapy. Endocrinol Metab Clin North Am 28: 801-823.

66. B Annabi, H Hiraiwa, BC Mansfield, KJ Lei, T Ubagai, et al. (1998) The gene for glycogen-storage disease type $1 \mathrm{~b}$ maps to chromosome 11q23. Am J Hum Genet 62: 400-405.

67. Veiga-da-Cunha M, Gerin I, Van Schaftingen E (2000) How many forms of glycogen storage disease type I? Eur J Pediatr 159: 314-318.

68. Mortellaro C, Garagiola U, Carbone V, Cerutti F, Marci V, et al. (2005) Unusual oral manifestations and evolution in glycogen storage disease type lb. J Craniofac Surg 16: 45-52.

69. Zeidler C, Germeshausen M, Klein C, Welte K (2009) Clinical implications of ELA2-, HAX1- and G-CSF-receptor (CSF3R) mutations in severe congenital neutropenia. $\mathrm{Br} \mathrm{J}$ Haematol 144: 459-467.

70. Phil J Ancliff, Rosemary E Gale, Ri Liesner, Ian M Hann, David C Linch (2001) Mutations in the ELA2 gene encoding neutrophil elastase are present in most patients with sporadic severe congenital neutropenia but only in some patients with the familial form of the disease. Blood 98: 2645-2650.

71. Bellanné-Chantelot $C$, Clauin S, Leblanc T, Cassinat B, Rodrigues-Lima F, et al. (2004) Mutations in the ELA2 gene correlate with more severe expression of neutropenia: $A$ study of 81 patients from the French Neutropenia Register. Blood 103: 4119-4125.

72. Ye Y, Carlsson G, Wondimu B, Fahlén A, Karlsson-Sjöberg $\mathrm{J}$, et al. (2011) Mutations in the ELANE gene are associated with development of periodontitis in patients with severe congenital neutropenia. J Clin Immunol 31: 936-945.

73. Andersson M, Karlsson J, Carlsson G, Pütsep K (2007) Expression of granule-associated proteins in neutrophils from patients with severe congenital neutropenia. Blood 110: $2772-2773$.

74. Alaluusua S, Kivitie-Kallio S, Wolf J, Haavio ML, Asikainen S, et al. (1997) Periodontal findings in cohen Syndrome with chronic neutropenia. J Periodontol 68: 473-478.

75. Abel MD, Carrasco LR (2006) Ehlers-danlos syndrome: Classifications, oral manifestations, and dental considerations. Oral Surg Oral Med Oral Pathol Oral Radiol Endod 102: $582-$ 590.

76. Nualart Grollmus ZC, Morales-Chávez MC, Silvestre Donat FJ (2007) Periodontal disease associated to systemic genetic disorders. Med Oral Patol Oral Cir Bucal 12: E211-E215.

77. Kapferer-Seebacher I, Pepin M, Werner R, Aitman TJ, Nordgren A, et al. (2016) Periodontal ehlers-danlos syndrome is caused by mutations in $\mathrm{C} 1 \mathrm{R}$ and $\mathrm{C} 1 \mathrm{~S}$, which encode subcomponents $\mathrm{C} 1 \mathrm{r}$ and $\mathrm{C} 1$ s of complement. Am J Hum Genet 99: 1005-1014.

78. Cunniff C, Williamson Kruse L (1995) Ehlers-danlos syndrome, type VIII presenting with periodontitis and prolonged bleeding time. Clin Dysmorphol 4: 145-149.

79. Rahman N, Dunstan M, Teare MD, Hanks S, Douglas J, et al. (2003) Ehlers-Danlos syndrome with severe early-onset periodontal disease (EDS-VIII) is a distinct, heterogeneous disorder with one predisposition gene at chromosome 12p13. Am J Hum Genet 73: 198-204.

80. Chapple IL, Matthews JB, Thorpe GH, Glenwright HD, Smith $\mathrm{JM}$, et al. (2001) A new ultrasensitive chemiluminescent 
assay for the site-specific quantification of alkaline phosphatase in gingival crevicular fluid. J Periodontal Res 28: 266-273.

81. Terkeltaub RA (2001) Inorganic pyrophosphate generation and disposition in pathophysiology. Am J Physiol Cell Physiol 281: 1-11.

82. Price PA, Toroian D, Chan WS (2009) Tissue-nonspecific alkaline phosphatase is required for the calcification of collagen in serum: A possible mechanism for biomineralization. J Biol Chem 284: 4594-4604.

83. Whyte MP (2010) Physiological role of alkaline phosphatase explored in hypophosphatasia. Ann N Y Acad Sci 1192: 190-200.

84. Mornet E (2007) Hypophosphatasia. Orphanet J Rare Dis 2: 40 .

85. Chapple IL (1993) Hypophosphatasia: Dental aspects and mode of inheritance. J Clin Periodontol 20: 615-622.
86. Watanabe $\mathrm{H}$, Goseki-Sone $\mathrm{M}$, limura $\mathrm{T}$, Oida $\mathrm{S}$, Orimo $\mathrm{H}$, et al. (1999) Molecular diagnosis of hypophosphatasia with severe periodontitis. J Periodontol 70: 688-691.

87. Wei KW, Xuan K, Liu YL, Fang J, Ji K, et al. (2010) Clinical, pathological and genetic evaluations of Chinese patients with autosomal-dominant hypophosphatasia. Arch Oral Biol 55: 1017-1023.

88. van den Bos T, Handoko G, Niehof A, Ryan LM, Coburn SP, et al. (2005) Cementum and dentin in hypophosphatasia. J Dent Res 84: 1021-1025.

89. Stabholz A, Soskolne WA, Shapira L (2010) Genetic and environmental risk factors for chronic periodontitis and aggressive periodontitis. Periodontol 2000 53: 138-153.

90. Ye Y, Carlsson G, Agholme MB, Wilson JA, Roos A, et al. (2013) Oral bacterial community dynamics in paediatric patients with malignant chemotherapy-related oral mucositis: A prospective study. Clin Microbiol Infect 19: E559-E567. 